International Journal of Behavioral Research \& Psychology (IJBRP)

ISSN 2332-3000

\title{
A Study On Association Among Sleep Pattern, Sleep Disturbance And Problem Behavior In Persons With Developmental Disabilities In India
}

Ganaie, S.A

Research Article

Research Scientist \& Rehabilitation Psychologist, Founder \& Executive Director of ASK-NGO GBL J\&K India

\section{Abstract}

Background: Sleep patterns of persons with developmental disabilities are different from those of age matched peers. Persons with developmental disabilities are taking more time to fall asleep as compared with other persons without disabilities (Piazza, Fisher, \& Kahng, (1996). Sleep disturbances seem to decrease one's ability to regulate, control, or inhibit emotion and behavior (Dahl, 1996, Wolfson and Carskadon, 1998). Brylewski and Wiggs (1999) found that persons with developmental disabilities with sleep disorders have more daytime problem behaviors like Irritability, Stereotypy, Hyperactivity, self-injury, aggression and screaming.

Methods: The present study assessed the sleep pattern, sleep disturbance and problem behavior in a randomized sample of persons $(\eta=70)$ with developmental disabilities on whom EEG recording was done. Persons with developmental disabilities who are living in community with parents were taken for the study. Semi-structured interviews were conducted to collect research data from informants on Demographic Data Sheet, Showkat's Screening Scale for Sleep Pattern of Children (SSSSPC), Sleep Disturbance Scale for Children (SDSC) and Behavioral Assessment scale for Indian Children with Mental Retardation Part-B. The relationships were explored among sleep pattern, sleep disturbance and problem behavior with respect to EEG record, medication and comorbid conditions in persons with developmental disabilities.

Results: Pearson's correlation co-efficient $(r)$ was calculated and it was found that sleep pattern is significantly associated with sleep disturbance $(r=0.534, \mathrm{p}<0.01))$ and problem behavior $(r=0.521, \mathrm{p}<0.01)$ of persons with developmental disabilities. The results showed that sleep pattern is significant with problem behaviors like temper tantrums \& misbehavior with others. Furthermore, persons with developmental disabilities having severe problems in sleep pattern also showed severe problem behaviors, such as self injurious behavior, repetitive behavior, odd behavior, hyperactivity \& rebellious behavior. The significant difference $(p<0.05)$ was found in sleep pattern of persons with developmental disabilities between the groups having normal EEG record and abnormal EEG record. Similar findings were also observed with respect to problem behavior. Results of this study are discussed pertaining to the assessment of sleep pattern; sleep disturbance and problem behavior of persons with developmental disabilities.

Conclusions: Present research study concluded that there is an association among sleep pattern, sleep disturbance and problem behavior in persons with developmental disabilities. In present study it was observed that there is a significant difference in sleep pattern of persons with developmental disabilities between the groups having normal EEG record and abnormal EEG record. Similar findings were also observed with respect to problem behavior.

Keywords: Developmental Disabilities; Sleep Disturbance; Sleep Pattern; Problem Behavior and EEG Record; Comorbidity.

\section{*Corresponding Author:}

Showkat Ahmad Ganaie,

Research Scientist \& Rehabilitation Psychologist,

Founder \& Executive Director of ASK-NGO GBL J\&K India.

E-mail: rcirehabilitationpsychologist@gmail.com;

\section{Received:}

Accepted: March 08, 2014

Published: March 10, 2014

Citation: Ganaie, S.A (2014) A Study on Association Among Sleep Pattern, Sleep Disturbance and Problem Behavior in Persons With Developmental Disabilities in India. Int J Behav Res Psychol. 2(2), 18-26. doi: http:/ /dx.doi.org/10.19070/2332-3000-140005

Copyright: Ganaie, S. $\mathbf{A}^{\circ}$ 2014. This is an open-access article distributed under the terms of the Creative Commons Attribution License, which permits unrestricted use, distribution and reproduction in any medium, provided the original author and source are credited.

\section{Introduction}

According to Developmental Disabilities Act of 2000, "Developmental Disabilities" means a severe, chronic disability of an individual that is attributable to a mental or physical impairment or combination of mental and physical impairments that are manifested before the individual attains 22 years of age and are likely to continue indefinitely. Developmental disabilities result in substantial limitations in three or more of the fallowing functional areas: self care, receptive, expressive language, learning, mobility, self direction, capacity for independent living and economic self sufficiency.

Developmental disability is a disability that is attributable to mental retardation, cerebral palsy, epilepsy, autism, or any other neurologically handicapping condition closely related to mental retardation and that requires treatment similar to that required by persons with mental retardation (State of Montana 2002). 
The present study has focused on developmental disabilities especially mental retardation, autism and epilepsy. The definitions of mental retardation, autism and epilepsy are as under:

According to Person with Disability (Equal Opportunities, Protection of Right, and Full Participation) Act 1995, Mental Retardation is defined "as a condition of arrested or incomplete development of mind of a person which is characterized by subnormality of intelligence."

According to Diagnostic and Statistical Manual of Mental Disorders (DSM)-IV-TR.-2010), "Mental Retardation is a disability characterized by significant limitations both in intellectual functioning and in adaptive behavior as expressed in conceptual, social and practical adaptive skills".

According to National Trust Act for the welfare of persons with autism, cerebral palsy, mental retardation and multiple disabilities Act (1999), "Autism means a condition of uneven skill development primarily affecting the communication and social abilities of a person, marked by repetitive and ritualistic behavior".

The International League against Epilepsy (ILAE) and the International Bureau for Epilepsy (IBE) has given the definitions for the terms of epileptic seizure and epilepsy in 2005. An epileptic seizure is a transient occurrence of signs and or symptoms due to abnormal excessive or synchronous neuronal activity in the brain. Epilepsy is a disorder of the brain characterized by an enduring predisposition to generate epileptic seizures and by the neurobiological, cognitive, psychological, and social consequences of this condition. The definition of epilepsy requires the occurrence of at least one epileptic seizure.

According to the Epilepsy Foundation of America, epilepsy is a physical condition that occurs when there is a sudden, brief change in how the brain works. When brain cells are not working properly, a person's consciousness, movement, or actions may be altered for a short time. These physical changes are called epileptic seizures. Epilepsy is therefore sometimes called a seizure disorder. Epilepsy affects people in all nations and of all races.

Sleep is a reversible state of behavioral quietness and lack of responsiveness to normal stimuli. It is opposite to the state of the wakefulness where there is an awareness of the surrounding environment and normal responsiveness to stimuli is present. Sleep is a necessary process for the survival of the human.

Sleep is a natural periodic suspension of consciousness needed to revive the body (The Gale Encyclopedia of Childhood and Adolescence$3^{\text {rd }}$ edition 1996). Sleep is a state of brain characterized by partial or total suspension of consciousness, muscular relaxation and inactivity, reduced metabolism and relative insensitivity to stimulation. Other mental and physical characteristics that distinguish sleep from wakefulness include amnesia for events occurring during the loss of consciousness and unique sleep related electroencephalogram and brain imaging patterns. These characteristics also help distinguish normal sleep from a loss of consciousness due to injury, disease or drugs (APA Dictionary of Psychology 2007).

Sleep is important for the consolidation of memory and learning, enhancement of metabolic and inflammatory responses, and improvement in growth and development. The implications for vulnerable children with atypical development are even more ra- tional as they tend to spend more time without sleep than typically developing children.

Sleep is a vital part of child and adolescent development. Poor or inadequate sleep can have a dramatically negative impact on a child's daily functioning, particularly school performance. Side effects may include off-task behavior, drowsiness, irritability and an inability to focus.

Sleep is a fundamental part of life. It is not just a function of the body, it is an active process. Sleep is so vital to the body's daily functioning that a prolonged loss of sleep impairs metabolism, immune function, temperature control and can ultimately lead to death (Rechtshaffen \& Bergmann, 2002).

Sleep patterns refer to a profile of the amount, timing, and quality of sleep that is typical for any given individual over a period of time. Comprehensive analyses of sleep patterns should incorporate polysomnographic recordings (e.g. actigraphy, EEG) during sleep. However, only a few studies have evaluated sleep patterns of individuals with developmental disabilities (cf. Espie et. al.1998).

Sleep onset and sleep maintenance problems in children with Intellectual Disabilities are usually associated with other behavioral problems and communication difficulties that affect the development of and maintenance of sleep-wake routines (Richdale, 1999). Impaired sleep quantity or quality has profound effects on daytime mood, behavior, cognition, general performance and physiology. When sleep disturbance is present in children it impacts not only upon the child's daytime functioning but also on that of the parents and the family at large, associations between childhood sleep problems and maternal stress, depression, poor marital relationships and even child abuse have been reported (Clement Dukes (1905). Sleep problems in school-aged children are primarily reported by parents, children as young as eight years old may be able to provide reliable information about their own sleep patterns, sleep hygiene, and sleep disturbances (Dr. Meltzer). Difficulties with sleep awakenings may foreshadow later problems with physiological, emotional, and behavioral self-regulation (Dabl, 1996, Dearing, Taylor, \& McCartney, 2004, Gregory, Caspi, Eley, Moffitt, O'Connor, \& Poulton, 2005, Lozoff, Wolf, \& Davis, 1984, Richman, 1981, Frank, Issa, \& Stryker, 2001, Thunstrom, 2002).

\section{Sleep problems in persons with developmental disabilities has adverse consequences}

Problems include reluctance to go to sleep, waking up in the middle of the night, nightmares, sleep walking and bed wetting. Many school children who are studying in $6^{\text {th }}$ grade may suffer adverse cognitive, behavioral and emotional consequences due to increased risk of being chronically sleep deprived (Robert $M y$ ers). Sleep difficulties among children with other developmental disabilities indicates significant variability between the different disorders. For example, children with Prader-Willi syndrome have extended nighttime sleep and daytime sleepiness, while children with Rett syndrome have difficulty staying asleep during the night and frequent daytime napping (Nestor Lopez. Duran-Ph.D in July 2008). Sleep disturbance refer to a variety of conditions in which people with ID experience disruptions in sleep, such as sleep apnea, restless legs syndrome, insomnia, and night awakenings. Some types of sleep problems (e.g., sleep apnea and restless legs syndrome) primarily reduce REM sleep, while difficulty falling asleep and night awakenings have a greater impact on Slow-Wave Sleep (SWS, Pace-Schott \& Hobson, 2002). 
The negative effects of sleep deprivation include reduced attention, impaired memory, increased stress response, and altered immune system functioning (Stickgold, Hobson, Fosse, \& Fosse, 2001). Children who have intellectual disability (ID), particularly those with severe ID, are reported to experience higher rates of sleeping problems than typically developing children. They are also reported to present with these problems with greater frequency and severity. It is thought that children with ID have difficulty in developing "the calming and necessary rhythms of rest and activity that allow synchrony with parents and carers" (Dorris et al., 2008). Daytime sleepiness may interfere with the effectiveness of the child's educational and behavioral programs. Sleep problems in children often disrupt the entire family's sleep, potentially leading to added daytime stress and irritability for all family members Quine, 1991). It is important to understand parental concerns about sleep in this population of children, much research have been done in the normally developing population, to provide a framework in which professionals may offer guidance. Some researchers have been hypothesized that some of the symptoms peculiar to autism may be directly associated with disturbed sleep (Johnson, 1996, Patzold et al. 1998, Richdale, 1999).

Improved sleep in a group of children with autism preceded improvement in social relatedness, reduced insistence on sameness, and adaptation to a novel environment (Segawa et al. 1992). Intervention for sleep disturbance influencing problem behavior involves the remediation of sleep disturbance through sleep hygiene routines (Durand, 1998), psychopharmacology (Roth, Hajak, \& Ustun, 2001), or a combination of the two.

\section{Sleep problems of parents having children with sleep problem}

Wiggs and Stores (1996) found that of those parents whose child had a sleep problem, $64 \%$ felt that they were not getting enough sleep themselves as compared to only $21 \%$ of the parents whose child had no sleep problem. Consistent with these figures, Quine (1991) found that $32 \%$ of parents of children with developmental disabilities reported that they rarely got enough sleep as a result of the child's sleep problem. Quine (1992) found that the more severe the child's sleep problem, the more negative were the mothers' feelings towards the child.

\section{Problem behaviors}

Problem behaviors may place an onerous burden on families, particularly as children grow from preschool into school age Bristol et al 1993).

Problem behaviors such as property destruction, physical aggression, self-injury and tantrums are major barriers to effective social and educational development (Horner et al 2000, Riechle 1990)". Such behaviors put young children at risk for exclusion and isolation from social, educational, family and community activities (Sprague and Rian 1993).

According to Marfatia (1971), "Problem behaviors in children are not disease entities but symptoms or reaction caused by emotional disturbances or environmental maladjustment".

The definition of problem behavior depends on whether "the behaviors are considered from the perspective of a child with developmental disability or from the perspective of a parent or teacher".

\section{Behavior from a child's perspective}

Problem behaviors include the inability to understand demands of a classroom or a parent and to communicate his or her needs and wants, severe difficulty in initiating and maintaining social interactions and relationships, confusion about the effects and consequences of many of his or her behaviors and engagement in restrictive, repetitive behaviors and interests that may limit the child's ability to learn and to fit with peers.

\section{Behavior from a parents or teachers perspective}

Problem behaviors include lack of compliance with or disruption of class room routines, tantrums, destruction of property and aggression against self or others.

Children with developmental disabilities show behavior that is considered as problematic because of the harm or inconvenience they cause for others, or to the child himself/herself. These problem behaviors could be due to a number of reasons. From behavior point of view, it may be due to lack of communication skills, cognitive skills or problem solving skills etc. It may be due to wrong handling of a child by people in the environment also.

The problem behavior in children with intellectual disabilities is strongly related to the sleep deprivation and the children will exhibit problem behaviors during their daily scheduled routines, but mostly affected when the young children missed their afternoon naps (O'Reilly and Lancioni 2000). The problem behavior in children with intellectual disabilities is strongly related to the sleep deprivation and the children will exhibit problem behaviors during their daily scheduled routines, but mostly affected when the young children missed their afternoon naps (O'Reilly and Lancioni 2000). Attention problems, externalizing problems, and internalizing problems are all associated with sleep problems. Sleep disturbances seem to decrease one's ability to regulate, control, or inhibit emotion and behavior (Dabl, 1996, Wolfson and Carskadon, 1998). Thus, poor sleep may contribute to an increased level of these problems. Inattention and hyperactivity were associated with sleep-related breathing disorders among children referred to sleep centers (Guilleminault et al., 1981, 1982) and children who were seen in child psychiatry and general pediatrics clinics (Chervin et al., 1997). Conduct problems were positively related to symptoms of sleep disordered breathing, restless leg syndrome, or periodic leg movements during sleep (Chervin et al., 2003).

Poindexter and Bihm (1994) studied sleep patterns in a group of 103 institutionalized persons with profound mental retardation, almost all adults, and found that $38.8 \%$ had persistent patterns of short-sleep over a period of many months. Brylewski and Wiggs (1998) surveyed 205 persons, ages 18 years or over, living in community housing, with a response rate of $85.7 \%$. Results showed problems falling asleep in $26.8 \%$, night waking in $55.6 \%$, parasomnias in $14 \%$, and sleep-related breathing problems in $15 \%$. Parasomnias reported included sleep-talking, tooth grinding, waking screaming, head banging, nightmares, and sleepwalking.

Richdale (1999) described the establishment of a "mature sleepwake rhythm" as a "developmental phenomenon". In other words, children learn how to sleep and wake in a routine as their brain develops and matures. Typically developing infants move 
from a pattern of sleeping and waking that is "polyphasic" when they are newborn to a more settled pattern of a longer night time sleep with 2 short naps at about 3 months and then on to one nap per day by 12 months of age. By 4 years of age most children have given up their daytime sleep. Children's sleep-wake rhythm is usually influenced by the light-dark cycle and the child's daily routines such as eating and social activities. Sleep problems in typically developing children may include difficulty settling down to sleep, waking during the night, night terrors or nightmares and occur in about $30 \%$ of pre-school aged children. Sleep improves during middle childhood and continuing problems such as night waking or difficulty settling are usually treated behaviorally or with progressive rescheduling of the sleep-wake cycle.

Salzarulo and Chevalier (1983) reported in a survey of 218 children between two and 15 years of age, seen for pediatric or child psychiatric consultation, which assessed the frequency of sleep disorders. They found an incidence of 6.5\% for night terrors, $6.5 \%$ for sleep-rocking, 9.5\% for bruxism (tooth grinding), 17\% for enuresis (bed-wetting), 23\% for trouble falling asleep, 28\% for night-waking, 31\% for nightmares, and 32\% for sleep walking.

Wiggs and Stores (1996) conducted a survey research study on sleep of 209 children ages 5-16 years with severe learning disabilities. Forty-four percent of this sample had a current severe sleep problem most nights or every night, with an average duration of over seven years. Of the 25 children with autism in the group, 17 $(68.0 \%)$ had reported sleep problems, as did seven of the twelve with cerebral palsy. After careful assessment for general daytime behavior problems, these authors concluded that the children with current sleep disturbance had significantly more daytime behavior problems than did other children.

Richdale, Gavidia-Payne, Francis, and Cotton (2000) examined scores on several indices of sleep disorders on 52 children with mild to profound mental retardation and compared these scores to those from a control group of typically developing children. Overall, Richdale et al. found sleep disorders in $58.6 \%$ of the children, and between-group analyses revealed that both past $(66.7 \%)$ and present $(57.7 \%)$ sleep disorders were more common in children with developmental disabilities than in typically developing children.

Sadeh, A., Mindell, J.A., \& Owens, J. (2011) Conducted a study on sleep and sleep ecology during the first 3 years in 18 countries it was found that most infants (more than $80 \%$ ) from predominantly Asian countries shared a room with their parents throughout the first three years whereas in predominantly Caucasian countries about $50 \%$ of the infants shared a room with their parents during the first few months and these figures dropped sharply during the first year to around $10 \%$ at the beginning of the second year of life. While the practice of co-sleeping was probably very adaptive in times when basic sleep conditions (e.g., appropriate temperature, safety from predators) could not be taken for granted and infant mortality rates were extremely high, there is very little empirical evidence to support co-sleeping as the only "correct" approach to sleep in infants in modern society. Moreover, some evidence suggests that it may be harmful.

Although sharing a room with the child was the tradition and norm in the predominantly Asian countries in the study quoted above, the parents in these countries reported later bedtimes, shorter night time sleep and more night-waking, and were more likely to consider their child's sleep as a problem in comparison to parents in predominantly Caucasian countries. These findings are similar with other studies indicating that co-sleeping is usually associated with more fragmented sleep and less deep sleep for both infant and parents. Furthermore, some evidence suggested that co-sleeping is more stressful and associated with more intense responses to stress in infants than solitary sleep.

Dorris et al (2008) and Richadale (2009) reported that Children with intellectual disability (ID), particularly those with severe ID, are reported to experience higher rates of sleeping problems than typically developing children, (about $34-80 \%$ ). They reported that children with intellectual disabilities have problems with greater frequency and severity. They also reported that sleep onset and sleep maintenance problems in children with ID found that sleep problems are usually associated with other behavioral problems and communication difficulties that affect the development of and maintenance of sleep-wake routines (Richdale, 1999). It is thought that children with ID have difficulty in developing "the calming and necessary rhythms of rest and activity that allow synchrony with parents and carers" (Dorris et al., 2008).

Espie et al. (1998) investigated the sleep patterns of 28 adults with severe to profound mental retardation and seizure disorder. Twelve individuals lived in a family home, three in a community home, and thirteen in a residential facility. Data were collected for seven nights by caregivers who completed sleep diaries. In addition, EEG recordings were obtained on one night. Overall, these adults spent approximately $42 \%$ of each 24 -hr period in bed, but the quality of their sleep was questionable. Only 12 individuals (43\%) evidenced any REM-sleep, and total REM-sleep was only about 30 minute on average. Non REM-sleep was markedly impoverished. While organic factors (e.g., brain damage) could be related to reduce REM-sleep, an alternative explanation is that the frequent use of antiepileptic medications and other drugs (e.g., benzodiazepines) in this population might suppress the duration of REM-sleep.

Daytime problem behaviors may be associated with sleep disorders. Brylewski and Wiggs (1999) explored the association between sleep disorders and daytime problem behaviors in a sample of 205 adults with moderate to profound mental handicap who lived in community based group homes. Results showed that individuals with sleep disorders scored significantly higher on three of the five subscales of the Aberrant Behavior Checklist (ABC) (Aman, Singh, Steward, \& Field, 1985) (i.e., Irritability, Stereotypy, and Hyperactivity). Specific topographies of problem behavior, such as self-injury, aggression, and screaming were more severe in the sleep-disordered group. Wiggs en Stores (1996) also found that children with sleep disorders had higher scores on all factors of the ABC, except Inappropriate Speech.

Review of literature discloses that irregular sleep-wake pattern, sleep disturbances and sleep disorders are highly prevalent and persistent in persons with developmental disabilities. Persons with developmental disabilities appear to be at increased risk for sleep disorders as compared to persons without developmental disabilities. This difference in prevalence and severity may be explained in part by brain damage. However, this literature is concluding that the nature of the relationship among irregular sleep-wake patterns, sleep disorders, sleep disturbances, problem behaviors and other variables remains unclear. These studies provide data from correlational and meta-analytical studies. Some of these variables may be both a cause and an effect or neither a cause 
nor effect of sleep disorder. For example, sleep disorders may cause daytime problem behaviors, and vice versa. Furthermore, both variables may be related to an unknown third variable, such as medical problems (e.g., epilepsy). Despite uncertainties about the nature of these associations, identification of such variables is important in that this may enable one to predict the likelihood of irregular sleep-wake pattern, sleep disturbances \& sleep disorders and problem behavior in persons with developmental disabilities.

The association among sleep pattern, sleep disturbance and problem behavior are clearly demonstrated by research findings from western countries. But in India, this specific area of research got least attention from researchers. Hence, in this study an attempt will be made to explore the association among sleep pattern, sleep disturbance and problem behavior in persons with developmental disabilities in India. The socio-cultural factors have impact on sleep pattern thus most of the sleep oriented Questionnaires \& Scales from Western World have difficulty in measuring the sleep oriented behaviors in Indian population. This requires an indigenous tool to screen the sleep dependent behaviors. Earlier studies have focused primarily on medical model providing a limited scope for interventional strategies. Hence there is demand for intervention oriented methodologies. The present study will help us to develop a screening scale for the assessment of sleep pattern and its significance is to understand the association among sleep pattern, sleep disturbance and problem behavior in persons with developmental disabilities. The emphasis is on intervention techniques, which will determine the direction of behavior management in persons with developmental disabilities. The current study is following the principles of BIOPSYCHOSOCIAL MODEL. This study will change the vision of those professionals who are focusing on either medical model or social model only. Finally, effective implementation of evidence-based treatments not only eliminates sleep disturbances or sleep disorders but also improves quality of life. It is plausible that early intervention to establish appropriate sleep patterns may help to preempt sleep disorders and many negative consequences associated with the lack of efficient sleep in persons with developmental disabilities.

\section{Aim of The Study}

The aim of the study is to find out the association among sleep pattern, sleep disturbance and problem behavior in persons with developmental disabilities. To fulfill this aim researcher has developed a screening scale for the assessment of sleep pattern in persons with developmental disabilities.

\section{Objectives of The Study}

- To find out the (association) among sleep pattern, sleep disturbance and problem behaviors of persons with developmental disabilities.

- To compare sleep pattern, sleep disturbance and problem behaviors of persons with developmental disabilities with respect to EEG.

- To compare sleep pattern, sleep disturbance and problem behaviors of persons with developmental disabilities with respect to medication.

- To compare sleep pattern, sleep disturbance and problem behaviors of persons with developmental disabilities with respect to their comorbid condition.

- To compare sleep pattern, sleep disturbance and problem behaviors of persons with developmental disabilities with respect to socio-demographic variables like age, sex, education and monthly income of parents.

- To establish psychometric properties of Showkat's Screening Scale for the Sleep Pattern of Children.

\section{Hypothesis}

- There will be no association among sleep pattern, sleep disturbance and problem behaviors of persons with developmental disabilities.

- There will be no significant difference among sleep pattern, sleep disturbance and problem behaviors of persons with developmental disabilities with respect to EEG.

- There will be no significant difference among sleep pattern, sleep disturbance and problem behaviors of persons with developmental disabilities with respect to medication.

- There will be no significant difference among sleep pattern, sleep disturbance and problem behaviors of persons with developmental disabilities with respect to their comorbid condition.

- There will be no significant difference among sleep pattern, sleep disturbance and problem behaviors of persons with developmental disabilities with respect to socio-demographic variables like age, sex, education and monthly income of parents.

\section{Methodology}

The present study is an exploratory research with correlational design. The randomized sample of 70 persons with developmental disabilities has been collected on whom EEG recording was already done in 2013 at National Institute for the Mentally Handicapped (NIMH) Secunderabad. Out of 70 persons with developmental disabilities 39 has normal EEG record and 31 has abnormal EEG record. The age range of sample was 5 to 15 years.

\section{Tools Used In The Study}

- Demographic Data Sheet (DDS)

- Binet-Kamat Test of Intelligence (BKT)

- Vineland Social Maturity Scale (VSMS)

- $\quad$ Sleep Disturbance Scale for children (SDSC)

- Showkat's Screening Scale of Sleep Pattern for children (SSSSPC)

- Behavioral Assessment scales for Indian Children with Mental Retardation (BASIC-MR-B)

\section{Procedure of Data Collection}

In the present study data was collected from persons with developmental disabilities and from their parents attending follow-up services at general services of National Institute for the Mentally Handicapped, Secunderabad Andhra Pradesh. The participants in this study participated on the basis of their willingness to participate on voluntary basis. The participants gave their consent to participate in the study.

A demographic data sheet has been used to collect information about the demographic variables like age, sex, monthly income of parents, education and also about the other variables like Comorbid condition, medication and the diagnostic impression of 
EEG records of the persons with developmental disabilities. The Showkat's Screening Scale of Sleep Pattern for Children (SSSPC) and Sleep Disturbance Scale for Children (SDSC) were administered to collect data on sleep pattern and sleep disturbance of persons with developmental disabilities. The scoring of Showkat's Screening Scale of Sleep Pattern for Children is "Yes" and "No" in which "Yes" means problem in sleep pattern and "No" means no problem in sleep pattern. The scoring on Sleep Disturbance Scale for Children is 1, 2, 3, 4 and 5. The score " 1 " means "Never", "2" means "Occasionally", "3" means " Sometimes", "4" means "Often" and " 5 " means " Daily". Binet- Kamat Test of Intelligence (BKT) has been already administered to diagnose the level of developmental disability. In some cases Binet- Kamat Test of Intelligence was not applicable to administer because of speech and language impairment. Then Vineland Social Maturity scale (VSMS) was administered to know the level of developmental disability. On the VSMS child's social age was obtained by giving credits in months to each item child has passed. Experiments (Goblet and Barclay, American Journal of Mental Deficiency, May, 1963,) had shown a consistent and high correlation between VSMS social age and the Benet M.A., Doll reporting a correlation of $r=0.85$ and Peterson (1943) reporting an $r=0.96$ on a sample of normal children. Behavioral Assessment Scale for Indian children with Mental Retardation (BASIC-MR, Part-B) was administered on persons with developmental disabilities to collect data about problem behaviors. On the BASIC-MR Part-B, presence of problem behavior was marked by 1 (occasionally) and 2 (frequently) and absence by 0 (never). The researcher administered psychological tests in presence of parents of persons with developmental disabilities and parental interview was taken to get sufficient information.

\section{Classification of Data}

The data were classified according to the different variables studied. In first step the sample was divided into two groups, one group was persons with developmental disabilities having normal EEG reports (39) and another group was persons with developmental disabilities having abnormal EEG reports (31). The tools administered were Showkat's screening scale for sleep pattern of children (SSSSPC), sleep disturbance scale for children (SDSC) and BASIC-MR-B. The sample with and without comorbid conditions like without comorbid conditions (14) autism (11), epilepsy with speech and language pathology (36), ADHD (7), cerebral palsy (1) and childhood psychoses (1). Medication was divided into antiepileptic medication group (25), psychoactive medication group (31) and without medication group (14). The levels of developmental disabilities included mild, moderate, severe and profound. The socio-demographic variables included like age $(60-120$ Months=34, 120-180 Months=36). The age range of sample was 5-15years. Sex $(M=49, F=21)$, education (without education $=25$, special education $=18$, regular education $=27$ ), and parental monthly income (below $6000 \mathrm{INR}=54$, above 6000 INR=16).

\section{Data Analysis}

The analysis of data was done by using Statistical Package for Social Science version 17.0 (SPSS 17.0). Statistical techniques used for analyzing data were: calculating frequencies, percentages, Mean, Standard Deviation, t-test and One-way analysis of variance (ANOVA). Statistical tests used for testing significant difference with respect to independent variables like age, sex, education, parent's monthly income etc. Pearson's correlation coefficient was used to find out the relationship among sleep pattern, sleep disturbance and problem behaviors in persons with developmental disabilities.

\section{Results}

Table 1. Showing Frequency and Percentage of EEG recorded sample groups

\begin{tabular}{|l|l|l|l|}
\hline S. No. & Sample Group & Frequency & Percent \\
\hline 1 & Normal EEG-R Group & 39 & 55.7 \\
\hline 2 & Abnormal EEG-R Group & 31 & 44.3 \\
\hline & Total & 70 & 100.0 \\
\hline
\end{tabular}

The frequency and percent of EEG-R sample groups. In this study $39(55.7 \%)$ of sample have normal EEG reports and $31(44.3 \%$ ) sample have abnormal EEG reports.

\section{Table 2. Showing Frequency and Percentage of persons with developmental disabilities with respect to their chronological age}

\begin{tabular}{|l|l|l|l|}
\hline S. No. & Age Groups & Frequency & Percent \\
\hline 1 & Age between 60-120 Month & 34 & 48.6 \\
\hline 2 & Age between 120-180 Month & 36 & 51.4 \\
\hline & Total & 70 & 100.0 \\
\hline
\end{tabular}

The table shows that $48.6 \%$ persons with developmental disabilities have age range between 60 to 120 months and $51.4 \%$ of persons with developmental disabilities have age range between 120 to 180 months of chronological age.

Table 3. Shows Pearson's correlation co-efficient among sleep pattern (SSSSPC), sleep disturbance (SDSC) and problem behavior (BASIC-MR Part B) in persons with developmental disabilities.

\begin{tabular}{|l|l|l|l|}
\hline SCALES USED & SSSSPC & SDSC & BMR - B \\
\hline SSSSPC & 1 & $.534^{* *}$ & $.521^{* *}$ \\
\hline SDSC & $.534^{* *}$ & 1 & .209 \\
\hline BASIC -MR-B & $.521^{* *}$ & .209 & 1 \\
\hline
\end{tabular}

The table shows correlations among sleep pattern, sleep disturbance and problem behavior of persons with developmental disabilities. In order to measure correlations among variables Pearson's correlation coefficient was used. In this study the correlation of sleep pattern with sleep disturbance and problem behaviors of persons with developmental disabilities were found to be significant $(r=0.534$ and $r=0.521)$ at $p<0.01$ level of significance. Hence, sleep pattern (SSSPC) is positively correlated with sleep disturbance (SDSC) and problem behavior (BASIC-MR-B) of persons with developmental disabilities that means as the scores of irregular sleep pattern increases, sleep disturbance and problem behavior occurs more. The current study shows that the correlation between sleep disturbance and problem behavior is $(r=0.209)$ which is insignificant $(p>0.05)$, however the correlation of sleep disturbance (SDSC) and sleep pattern (SSSSPC) is significant $(p<0.01)$. The study shows that problem behavior (BASIC-MR-B) is also significant with sleep pattern $(p<0.01)$. The domain 1, 9 and 10 (Violent \& Destructive Behavior, Antisocial Behaviors and Fears) of BASIC-MR-Part B is insignificant $(p>0.05)$ with sleep pattern (SSSSPC) of persons with developmental disabilities. The domain 2 and 3 (Temper Tantrums \& Misbehaves with others) of BASICMR-Part B is significant $(p<0.05)$ with sleep pattern (SSSSPC) of 
persons with developmental disabilities. The domain 4, 5, 6, 7 and 8 (Self Injurious Behavior, Repetitive Behaviors, Odd Behaviors, Hyperactivity \& Rebellious Behavior) of BASIC-MR-Part B is significant $(p<0.01)$ with sleep pattern (SSSSPC) of persons with developmental disabilities. Thus, the hypothesis: There will be no association among sleep pattern (SSSSPC), sleep disturbance (SDSC) and problem behavior (BASIC-MR-B) in persons with developmental disabilities is rejected at 0.01 level of significance.

Table 4. Shows Mean, Standard Deviation and results of $t-$ test for Equality of Means in sleep pattern (SSSSPC), sleep disturbance (SDSC) and problem behavior (BASIC-MR-B) in persons with developmental disabilities with respect to normal and abnormal EEG records.

\begin{tabular}{|l|l|l|l|l|l|l|}
\hline Scales & Sample & N & Mean & S.D & $\begin{array}{l}\text { “t” } \\
\text { value }\end{array}$ & P-Value \\
\hline SSSSPC & N-EEG-R & 39 & 15.13 & 4.268 & & \\
\hline & Ab-EEG-R & 31 & 17.29 & 4.268 & 2.105 & $p<0.05$ \\
\hline SDSC & N-EEG-R & 39 & 44.41 & 6.112 & & \\
\hline & Ab-EEG-R & 31 & 45.16 & 5.550 & 0.532 & $p>0.05$ \\
\hline $\begin{array}{l}\text { BASIC- } \\
\text { MR-B }\end{array}$ & N-EEG-R & 39 & 36.05 & 12.812 & & \\
\hline & Ab-EEG-R & 31 & 45.45 & 18.334 & 2.522 & $p<0.05$ \\
\hline
\end{tabular}

The table shows mean and standard deviation of sleep pattern (SSSSPC), sleep disturbance (SDSC) and problem behavior (BASIC-MR-B) of persons with developmental disabilities with respect to normal and abnormal EEG record. The mean and standard deviation of sleep pattern of persons with developmental disabilities with respect to normal EEG recodrs $(M=15.13$, $\mathrm{SD}=4.268)$ and abnormal EEG reports $(\mathrm{M}=17.29, \mathrm{SD}=4.268)$, To find out whether there is any significant difference in mean scores of sleep pattern (SSSSPC) in persons with developmental disabilities with respect to their normal EEG record and abnormal EEG record. $t$-value was calculated. The obtained ' $t$ ' value is 2.105. Since the calculated value is more than the table value, it indicates that there is significant difference $(p<0.05)$ in sleep pattern (SSSSPC) of persons with developmental disabilities with respect to normal EEG record and Abnormal EEG record. The mean and standard deviation of sleep disdurbance in persons developmental disabilities with respect to normal EEG record $(\mathrm{M}=44.41, \mathrm{SD}=6.112)$ and abnormal $\mathrm{EEG}$ record $(\mathrm{M}=45.16$, $\mathrm{SD}=5.550$ ). To find out whether there is any significant difference in mean scores of sleep disturbance (SDSC) with respect to normal EEG record and abnormal EEG record of persons with developmental disabilities. t-value was calculated. The obtained $\mathrm{t}$-value is 0.532 . Since the calculated value is less than the table value, it indicates that there is no significant difference $(p>0.05)$ in sleep disturbance of persons with developmental disabilities with respect to normal EEG record and Abnormal EEG record. The mean and standard deviation of problem behaviors (BASIC-MRB) in persons developmental disabilities with respect to normal EEG record $(M=36.05, S D=12.812)$ and abnormal $E E G$ record $(\mathrm{M}=45.45, \mathrm{SD}=18.334)$. To find out whether there is any significant difference in problem behavior (BASIC-MR-B) mean scores of persons with developmental disabilities with respect to normal EEG record and abnormal EEG record. t-value was calculated. The obtained t-value is 2.522 . Since the calculated value is more than the table value, it indicates that there is significant difference $(p<0.05)$ in problem behavior of persons with developmental disabilities with respect to normal EEG record and Abnormal EEG record. Persons with developmental disabilities having irregular sleep pattern exhibited more problem behavior follwed by normal and abnormal EEG pattern.Thus, the hypothesis: There will be no significant difference among sleep pattern, sleep disturbance and problem behavior in persons with developmental disabilities with respect to normal and abnormal EEG record is rejected with respect to sleep pattern and problem behavior in persons with developmental disabilities $(\mathrm{p}<0.05)$, however on sleep disturbance, it is insignificant $(\mathrm{p}>0.05)$. Hence, it can be concluded that sleep pattern (SSSSPC) and problem behavior (BASIC-MR-B) in persons with developmental disabilities with respect to normal EEG recorded and abnormal EEG recorded sample group differs significantly.

Table 5: Shows mean, standard deviation and results of $t-$ test for Equality of Means in sleep pattern (SSSSPC), sleep disturbance (SDSC) and problem behavior (BASIC-MR-B) of persons with developmental disabilities with respect to their parent's monthly income

\begin{tabular}{|c|c|c|c|c|c|c|}
\hline Scales & $\begin{array}{l}\text { Monthly } \\
\text { Income }\end{array}$ & $\mathrm{N}$ & Mean & S.D & $\begin{array}{l}\text { " } t " \\
\text { value }\end{array}$ & P-Value \\
\hline \multirow[t]{2}{*}{ SSSSC } & Below 6000 & 54 & 16.26 & 4.226 & & \\
\hline & $\begin{array}{l}\text { Above } \\
6000\end{array}$ & 16 & 15.50 & 4.940 & 0.607 & $p<0.05$ \\
\hline \multirow[t]{2}{*}{ SDSC } & Below 6000 & 54 & 45.07 & 6.062 & & \\
\hline & $\begin{array}{l}\text { Above } \\
6000\end{array}$ & 16 & 43.63 & 5.032 & 0.870 & $p>0.05$ \\
\hline \multirow{2}{*}{$\begin{array}{l}\text { BASIC- } \\
\text { MR-B }\end{array}$} & Below 6000 & 54 & 39.06 & 15.643 & & \\
\hline & $\begin{array}{l}\text { Above } \\
6000\end{array}$ & 16 & 44.13 & 17.439 & 1.109 & $p<0.05$ \\
\hline
\end{tabular}

The table shows mean and standard deviation of sleep pattern (SSSSPC), sleep disturbance (SDSC) and problem behaviour (BASIC-MR-B) of persons with developmental disabilities with respect to their parents monthly income. The mean and standard deviation of sleep pattern (SSSSPC) of persons with developmental disabilities with respect to their parents monthly income below 6000 INR is $\mathrm{M}=16.26, \mathrm{SD}=4.226$ and above $6000 \mathrm{INR}$ is $15.50, \mathrm{SD}=4.940$. The mean and standard deviation of sleep disturbance (SDSC) of persons with developmental disabilities with respect to their parents monthly income below 6000 INR is $\mathrm{M}=45.07, \mathrm{SD}=6.062$ and above $6000 \mathrm{INR}$ is 43.63, $\mathrm{SD}=5.032$. The mean and standard deviation of problem behavior (BASICMR-B) of persons with developmental disabilities with respect to their parents monthly income below $6000 \mathrm{INR}$ is $\mathrm{M}=39.06$, $\mathrm{SD}=15.643$ and above $6000 \mathrm{INR}$ is $44.13, \mathrm{SD}=17.439$. To find out whether there is any significant difference in mean scores of sleep pattern (SSSSPC) with respect to parent's monthly income (below 6000 and above $6000 \mathrm{INR}$ ) of persons with developmental disabilities. $\mathrm{t}$-value was calculated. The obtained $\mathrm{t}$-value is 0.607 , since the calculated value is less than the table value, it indicates that there is no significant difference $(\mathrm{p}>0.05)$ in sleep pattern (SSSSPC) of persons with developmental disabilities with respect to parents monthly income. To find out whether there is any significant difference in mean scores of sleep disturbance (SDSC) with respect to parent's monthly income (below 6000 and above $6000 \mathrm{INR})$ of persons with developmental disabilities. $t$-value was calculated. The obtained $t$-value is 0.870 , since the calculated value is less than the table value, it indicates that there is no significant difference $(\mathrm{p}>0.05)$ in sleep disturbance (SDSC) of persons with developmental disabilities with respect to parents monthly income. To find out whether there is any significant difference in mean scores of problem behavior (BASIC-MR-B) with respect to parent's monthly income (below 6000 and above 6000 INR) 
of persons with developmental disabilities. t-value was calculated. The obtained t-value is 1.109 , since the calculated value is less than the table value, it indicates that there is no significant difference $(p>0.05)$ in problem behavior (BASIC-MR-B) of persons with developmental disabilities with respect to parents monthly income. Thus, the hypothesis: There will be no significant difference among sleep pattern, sleep disturbance and problem behavior in persons with developmental disabilities with respect to parent's monthly income is accepted.

\section{Discussion}

The present study revealed that there is a positive correlation between sleep pattern \& problem behavior and similar finding has been observed between sleep pattern and sleep disturbance in persons with developmental disabilities. Poindexter and Bihm (1994) found that sleep patterns in a group of institutionalized persons with profound mental retardation, almost all adults had $38.8 \%$ persistent patterns of short-sleep over a period of many months. Brylewski and Wiggs (1998) found in a survey of 205 persons, ages 18 years or over, living in community housing, with a response rate of $85.7 \%$. Results showed that problems in falling asleep in $26.8 \%$, night waking in $55.6 \%$, parasomnias in $14 \%$, and sleep-related breathing problems in 15\%. Parasomnias reported included sleep-talking, tooth grinding, waking, screaming, head banging, nightmares, and sleepwalking. Aman, Singh, Steward, \& Field, 1985 found that Irritability, Stereotypy, Hyperactivity and some specific topographies of problem behavior, such as selfinjury, aggression, and screaming were more severe in the sleepdisordered group. Sleep onset and sleep maintenance problems in children with Intellectual Disabilities are usually associated with other behavioral problems and communication difficulties that affect the development of and maintenance of sleep-wake routines (Richdale, 1999). Results from several research studies have yielded a relationship between sleep problems and daytime problem behaviors (e.g., Richdale, Cotton, \& Hibbitt, 1999, Quine, 1991, Wiggs \& Stores, 1996a). Daniel J. Gottlieb, MD, Michael J. Corwin, MD (2003) and others conducted a study in which parents reported hyperactivity $(19 \%)$ and inattention (18\%) were common, with aggressiveness (12\%) and daytime sleepiness (10\%) reported somewhat less often. Sleep disordered breathing symptoms were present in 744 (25\%) children Compared with children without snoring or other symptoms of Sleep disordered breathing, children with Sleep disordered breathing symptoms were significantly more likely to have parent-reported daytime sleepiness and problem behaviors, including hyperactivity, inattention, and aggressiveness. Sleep problems are common in children with developmental disabilities. Such problems may be divided into problems with the sleep-wake cycle (i.e., dyssomnias), such as settling difficulties, frequent night waking, excessive sleepiness, and early waking, and unusual behaviors during the night (i.e., parasomnias), such as teeth grinding, and night terrors (e.g., Stores, 1996).

The present study found significant difference in sleep pattern of persons with developmental disabilities between the groups having normal EEG record and abnormal EEG record. Similar findings were also observed with respect to problem behavior. According to Bernard L. Maria (20005) the relationship between sleep and epilepsy can be seen in the impact of sleep on the risk for seizure recurrence, in one prospective pediatric study, 1 st seizures occurred when the child was apparently asleep in just over one-half of the cases evaluated. The likelihood of a second unprovoked seizure (i.e., epilepsy) was much higher if the 1 st event was sleep in children without any risk factors and a normal elec- troencephalogram (EEG). Sleep-related seizures recurred in 42\% of cases, whereas only $18 \%$ of the children. Sleep deprivation is an important predisposing factor in seizure activity, and the effect can be used to increase the yield of EEG abnormalities, pathologic findings increased from 7.5 to $24 \%$ after overnight sleep deprivation in one large study. The rate of paroxysmal discharges increased from 50 to $80 \%$ after one night of missed sleep in patients with recognized epilepsy. Approximately one-third of individuals with definite clinical epilepsy but normal or borderline routine waking EEG will show unequivocal epileptiform EEG abnormalities after sleep deprivation. Children who have irregular sleep-wake patterns show more daytime problem behaviors than children without irregular sleep-wake.

In present study researcher found that sleep pattern is significant with problem behaviors like temper tantrums \& misbehavior with others. Furthermore, persons with developmental disabilities having severe problems in sleep pattern showed more severe levels of daytime problem behaviors, such as self injurious behavior, repetitive behavior, odd behavior, hyperactivity \& rebellious behavior. The present study also found that there is a significant difference in sleep pattern of persons with developmental disabilities between the groups having normal EEG record and abnormal EEG record. Similar findings were also observed with respect to problem behavior.

\section{Conclusion}

Research into sleep pattern, sleep disturbance and problem behavior in persons with developmental disabilities is still in its infancy. At present, there is no standardized diagnostic system with which sleep problems in persons with developmental disabilities may be classified. The question whether sleep characteristics and sleep needs in persons with developmental disabilities are comparable to those of normally developing peers remains to be answered. The severity of a sleep problem is assessed taking into account its duration (i.e., exists for longer than one month), its frequency (e.g., more than three nights a week), and its adverse effects on both the persons with developmental disabilities and his/her parents. Many persons with developmental disabilities lack communicative abilities to inform caregivers about their sleep preferences and sleep problems. In addition, parents may be uninformed about what constitutes a sleep problem. Therefore, sleep problems may remain 'undiagnosed' or 'unrecognized' in persons with developmental disabilities. The present study tries to explore the association among sleep pattern, sleep disturbance and problem behavior in persons with developmental disabilities. The results of the present study are consistent with previous research findings. In present study researcher found that sleep pattern and sleep disturbance are positively correlated with problem behavior of persons with developmental disabilities. The sleep pattern and problem behavior in persons with developmental disabilities with respect to EEG record was found statistically significant in the present study. The sleep pattern, sleep disturbance and problem behavior in persons with developmental disabilities with respect to socio-demographic variables, medication and comorbid conditions were found statistically insignificant in the present study. The present study concluded that presence of irregular sleepwake pattern and sleep disturbances will increase the problem behavior in persons with developmental disabilities.

\section{References}

[1]. American Psychological Association. (2000). Diagnostic and statistical manu- 
al of mental disorders (4 $4^{\text {th }}$ ed. TR) Washington, DC: Author

[2]. Aman, M.G., Singh, N.N., Stewart, A.W., \& Field, C.J. (1985). The Aberrant Behavior Checklist: A behavior rating scale for the assessment of treatment effects. American Journal of Mental Deficiency, 89, 492-502.

[3]. Avrutskii, G. Ia., I. Ia. Gurovich, and V. V. Gromova (1974) Farmakoterapiia psikhicheskikh zabolevanii-Moscow.

[4]. Bartlett, L.B., Rooney, V., \& Spedding, S. (1985). Nocturnal difficulties in a population of mentally handicapped children. British Journal of Mental Sub normality, 31, 54-59.-37.

[5]. Brylewski, J. E. \& Wiggs, L. (1998). A questionnaire survey of sleep and night-time behavior in a community-based sample of adults with intellectual disability. Journal of Intellectual Disability Research, 42, 154-162

[6]. Brylewski, J., \& Wiggs, L. (1999). Sleep problems and daytime challenging behavior in a Community-based sample of adults with intellectual disabilities. Journal of Intellectual Disability Research, 43, 504-512.

[7]. Bramble, D. (1997). Rapid-acting treatment for a common sleep problem. Developmental Medicine and Child Neurology, 39, 543-547. Carr, E.G., \& Neumann, J.K. (1999). Graphic sleep monitoring: A clinical program to Improve sleep in residents with mental retardation. Journal of Developmental and Physical Disabilities, 11, 91-103.

[8]. Carroll, J. S., Bliwise, D. L., \& Dement, W. C. (1989). A method for checking interobserver reliability in observational sleep studies. Sleep, 12, 363-367.

[9]. Clements, J., Wing, L., \& Dunn, G. (1986). Sleep problems in handicapped children: A preliminary study. Journal of Child Psychology and Psychiatry, 27, 399-407.

[10]. Clements, J., Wing, L., \& Dunn, G. (1986). Sleep problems in handicapped children: A Preliminary study. Journal of Child Psychology and Psychiatry, 27, 399-407.

[11]. Comings, D. E. \& Comings, B. G. (1987). A controlled study of Tourette syndrome. VI. Early development, sleep problems, allergies, and handedness. American Journal of Human Genetics, 41, 822-838.

[12]. Dement, W. C. \& Mitler, M. M. (1993). It's time to wake up to the importance of sleep disorders. Journal of the American Medical Association, 269, 1548-1550.

[13]. Delay, J., P. Deniker, and J. Harl (1952). "Utilization en thérapeutique, psychiatrique d'une phénothiazine d'action centrale élective (4560 RP)." Annales medico-psychologiques, vol. 110(2), pp. 112-17.

[14]. Didden, R., Curfs, L., Sikkema, S., \& Moor, J. de (1998). Functional assessment and Treatment of sleep problems with developmentally disabled children: Six case studies. Journal of Behavior Therapy and Experimental Psychiatry, 29, 87-95.

[15]. Dorris, L., Scott, N., Zuberi, S., Gibson, N. amd Espie, C. (2008) Sleep problems in children with neurological disorders. Developmental neurorehabilitation. 1-20

[16]. Espie, C.A., Paul, A., McFie, J., Amos, P., Hamilton, D., McColl, J.H., Tarassenko, L., \& Pardey, J. (1998). Sleep studies of adults with severe or profound mental retardation and Epilepsy. American Journal on Mental Retardation, 103, 47-59.

[17]. Espie, C., \& Tweedie, F. (1991). Sleep patterns and sleep problems amongst people with mental handicap. Journal of Mental Deficiency Research, 35, 25 36.

[18]. Gale Encyclopaedia of Children's Health @ 2006 by the Gale Group, Inc. All rights reserved.

[19]. Gillin, J. C. \& Byerley, W. F. (1990). The diagnosis and management of insomnia. New England Journal of Medicine, 322, 239-248.

[20]. Koh, S., Ward, S., Lin, M., \& Chen, L. (2000). Sleep apnea improves seizure control in children with neurodevelopmental disorders. Pediatric Neurology, 22, 36-39.

[21]. Kupfer, D. J. \& Reynolds, C. F. (1997). Management of insomnia. New England Journal of Medicine, 336, 341-346.

[22]. La Voie, A. (1997, April 17). Insomnia and related problems show alarmingly high rates. Medical Tribune, p. 6

[23]. Laborit, H., P. Huguenard, and R. Alluaume (1952). "Un Nouveau Stabilisateur végétatif (Le 4560 RP).” Presse médicale, vol. 60, no. 10, pp. 206-08.

[24]. Leigh, T. J., Bird, H. A., Hindmarch, I., Constable, P. D. L., \& Wright, V. (1988). Factor analysis of the St. Mary's Hospital Sleep Questionnaire. Sleep, $11,448-453$.

[25]. Maria M. Wong, Kirk J. Brower, Hiram E. Fitzgerald, and Robert A. Zucker, Sleep Problems in Early Childhood and Early Onset of Alcohol and Other Drug Use in Adolescence.

[26]. McGraw-Hill Dictionary of Scientific \& Technical Terms, 6E, Copyright $(\odot$ 2003 by the McGraw-Hill Companies, Inc.

[27]. Okawa, M., Nanami, T., Wada, S., Shimizu, T., Hishikawa, Y., Sasaki, H., Nagamine, H., \& Takahashi, K. (1987). Four congenitally blind children with circadian sleep-wake rhythm disorder. Sleep, 10, 101-110.

[28]. O’Reilly, M.F. (1995). Functional analysis and treatment of escape-maintained aggression Correlated with sleep deprivation. Journal of Applied Be- havior Analysis, 28, 225-226.

29]. O’Reilly, M.F., \& Lancioni, G.E. (2000). Response covariation of escapemaintained aberrant Behavior correlated with sleep deprivation. Research in Developmental Disabilities, 21,125-136.-39

[30]. Pary, R., Tobias, C. R., Webb, W. K., \& Lippmann, S. B. (1996). Treatment of insomnia: Getting to the root of sleeping problems. Postgraduate Medicine, $100,195-210$.

[31]. Piazza, C.C., Fisher, W.W., \& Kahng, S.W. (1996). Sleep patterns in children and young Adults with mental retardation and severe behavior disorders. Developmental Medicine and Child Neurology, 38, 335-344.

[32]. Poindexter, A. R. \& Bihm, E. M. (1994). Incidence of short-sleep patterns in institutionalized individuals with profound mental retardation. American Journal on Mental Retardation, 98, 776-780.

[33]. Quine, L. (2001) Sleep problems in primary school children: comparison between mainstream and special school children. Child: Care, Health and Development, May 3: 201-21.

[34]. Quine, L. (1991). Sleep problems in children with mental handicap. Journal of Mental Deficiency Research, 35, 269-290.

[35]. Quine, L. (1992). Severity of sleep problems in children with severe learning disabilities: Description and correlates. Journal of Community $\backsim$ Applied Social Psychology, 2, 247-268

[36]. Reite, M. L., Nagel, K. E., \& Ruddy, J. R. (1990). Concise guide to the evaluation and management of sleep disorders. Washington, DC: American Psychiatric Press.

[37]. Richdale, A., Gavidia-Payne, S., Francis, A., \& Cotton, S. (1997, May). Sleep characteristics of children with an intellectual disability. Poster paper presented at the meeting of the American Association on Mental Retardation, New York, NY.

[38]. Richdale, AL. (1999). Sleep problems in Autism: Prevalence, cause and intervention. Developmental Medical Child Neurology. 41: 60-66.

[39]. Richdale, A.L., Cotton, S., \& Hibbitt, K. (1999). Sleep and behavior disturbance in Prader-Willi syndrome: A questionnaire study. Journal of Intellectual Disability Research, 43, 380-392.

[40]. Richdale, A., Gavidia-Payne, S., Francis, A., \& Cotton, S. (2000). Stress, behavior and sleep problems in children with an intellectual disability. Journal of Intellectual and Developmental Disability, 25, 147-161.

[41]. Salzarulo, P. \& Chevalier, A. (1983). Sleep problems in children and thei relationship with early disturbances of the waking-sleeping rhythms. Sleep, 6, 47-51.

[42]. Schalock, R. L. \& Lilley, M. A. (1986). Placement from community-based mental retardation programs: How well do clients do after 8 to 10 years? American Journal of Mental Deficiency, 90, 669-676.

[43]. Shibagaki, M., Kiyono, S., \& Matsuno, Y. (1985). Nocturnal sleep of severely mentally retarded children and adolescents: Ontogeny of sleep patterns. American Journal of Mental Deficiency, 90, 212-216.

[44]. Shibagaki, M., Kiyono, S., \& Takeuchi, T. (1985). Nocturnal sleep in mentally retarded infants with cerebral palsy. Electroencephalography and Clinical Neurophysiology, 61, 465-471.

[45]. Smith, A.C., Dykens, E., \& Greenberg, F. (1998). Sleep disturbance in Smith-Magenis Syndrome (del17 p11.2). American Journal of Medical Genetics, 81, 186-191.

[46]. Strollo, P. J. \& Rogers, R. M. (1996). Obstructive sleep apnea. New England Journal of Medicine, 334, 99-104.

47]. Stores, G., Wiggs, L., \& Campling, G. (1998). Sleep disorders and their relationship to Psychological disturbance in children with epilepsy. Child: Care, Health and Development, 24, 5-19.

[48]. Sudhalter V. (2001) Problem behaviors in individuals with developmental disabilities. In: Devinsky O and Westbrook LE, eds. Epilepsy and Developmental Disabilities. Boston: Butterworth-Heinemann, 165-174.

[49]. Symons, F., Davis, M., \& Thompson, T (2000). Self-injurious behavior and sleep disturbance in adults with developmental disabilities. Research in Developmental Disabilities, 21,115-123.

[50]. Wiggs, L. \& Stores, G. (1996). Severe sleep disturbance and daytime challenging behavior in children with severe learning disabilities. Journal of Intellectual Disability Research, 40, 518-528.

[51]. Wiggs, L., \& Stores, G. (1999). Behavioral treatment for sleep problems in children with severe learning disabilities and challenging daytime behavior: Effect on daytime Behaviour. Journal of Child Psychology and Psychiatry, 40 627-635.

[52]. Wiggs, L., \& Stores, G. (1996b). Sleep problems in children with severe intellectual Disabilities: What help is being provided? Journal of Applied Research in Intellectual Disabilities, 9, 159-164.

[53]. Young, T., Palta, M., Dempsey, J., Skatrud, J., Weber, S., \& Badr, S. (1993). The occurrence of sleep-disordered breathing among middle-aged adults. New England Journal of Medicine, 328, 1230-1235. 